\title{
A Roadmap for the Adoption of Government E-payments in Kenya
}

\author{
Bonface I. Asiligwa \\ School of Computing and Informatics, \\ University of Nairobi, Kenya
}

\author{
Elijah I. Omwenga \\ School of Computing and Informatics, \\ University of Nairobi, Kenya
}

\begin{abstract}
Analogous to the Motorists roadmap that shows the roads, directions and distances to a destination of a given region [1]. A roadmap in this context is a detailed guideline that answers the "why-what-how" questions and lay out the required actions, the "to-do's." towards adoption of e-payments in the government of Kenya. For Over a decade, the government of Kenya grappled with the idea of implementing a national payment gateway through which all payments for government services, levies, duties, and fines were to be electronically made. For a long period industry players and policy makers in government had unsuccessfully developed varied strategies of achieving a cashless government payment system. These efforts have failed to yield due to lack of a comprehensive roadmap that addressed pertinent issues that had to be dealt with for e-payments in government to be fully adopted.
\end{abstract}

This research was done by conducting a survey study on the government of Kenya on the adoption of e-payments.

A random sample of the research population was drawn from ICT and Finance employees of 262 state corporations, 19 Ministries, and 47 counties to which a questionnaire was administered to gain an understanding and information on why there had been low uptake of e-payments in the government of Kenya. The data collected was analyzed quantitatively and qualitatively using descriptive statistical techniques. The results from this analysis have been used to propose a roadmap for the adoption of e-payments in the government of Kenya and any other similar setting.

\section{General Terms}

ICT, Payment systems, Government, payment gateway

\section{Keywords}

Adoption, Roadmap, Change management, e-Payments, egovernment, Adoption, Stakeholder engagement, information security

\section{INTRODUCTION}

For over 10 years, progress has been made in automating government payment systems and financial services systems in general. Government e-payment system is geared towards harmonizing the financial payments system intended to market Kenya as a financial hub in the region and a preferred investment option to reduce cost of business, increase efficiency, improve transaction accounting, increase revenue collection and eliminate corruption [2].

The sheer volume and variety of payments government agencies must contend with, coupled with a heightened focus on transparency, security and compliance, makes the government e-payments unique and hence the need for epayments in government

Although the government of Kenya had made efforts towards realizing an integrated cashless system through enactment of various legislations [3], very little gains had been achieved due to very low uptake of the e-payments platforms provided. This was attributed to lack of a roadmap or universal guide that provided a management centric approach that offered clear guidelines on how e-payments should be implemented while taking into account the unique requirements of different Ministries, Departments and Agencies (MDA). There has been wrong perceptions of government e-payments and outright resistance by some MDAs and mistrust among government agencies on which MDA should own and operate the Kenya national payment gateway through which government e-payment were to be done. Some government entities implemented their own payment gateways. At one time, Kenyan government directed all government agencies to adopt Kenya Posts Corporation's Posta Pay for e-payments via the e-citizen portal but this did not materialize. Through the e-citizen portal, Kenya also made an effort to automate its payments using Mobile money but the portal experienced technical problems due to sizing and ownership issues. Even though the e-citizen portal had been up for more than one year, very few government services could be paid for through this portal.

In quest to provide a lasting solution to these issues, this research sought to establish reasons for slow adoption of government e-payment systems in Kenya, evaluated the adequacy of existing government e-payment frameworks and suggested improvement, Developed a roadmap for adoption of e-payments in the government of Kenya and gained an understanding of the impact of change management, stakeholder engagement, ICT infrastructure, e-payments awareness and information security on adoption of epayments in the government of Kenya.

\section{RELATED WORK ON E-PAYMENTS AND TECHNOLOGY ADOPTION ROADMAPS}

As e-payments continue to take off in the public and private sectors, governments' commitment to the uptake of e-payment systems will continue to be crucial [4]. Governments around the world are increasingly using electronic platforms to collect taxes, procure goods, services, and other key transactions as part of a global shift away from cash payments [4]. Governments are also adopting innovative solutions to epayments, including mobile payments systems, which may increase access to services by the unbanked [4]. People to Government (P2G) and Government to people (G2P) Payments remain the focus area in government e-payment service [3]. India is among one of the developing countries that has implemented e-payment services in government successfully [5]. 


\subsection{Types of E-payment Systems}

There are seven main types of electronic payment systems, Debit card, Credit Card, Smart Card, Electronic Cash, Electronic Cheques and Mobile Money [5].

\subsection{E-Payments in Governments}

There are several challenges affecting adoption of e-payments in developing countries' governments. This include:- Lack of adequate and reliable infrastructure, Security concerns by the population, Inadequate skills due to low levels of computer literacy, Lack of legal and institutional frameworks in governments on e-payments ,Integration issues ,Lack of knowledge and awareness on e-payments, Lack of trust in electronic payments [6]. Though the legal and regulatory framework had been dealt with through the enactment of Kenya national payment systems act of 2011 [7], the act fell short of addressing several issues like custodianship of the payment systems. Other than the legal framework, the issues above were to larger extent technical issues that did not address the human factors. Stake holder engagement and change management should also be considered for effective adoption of e-payments in government [8]. For effective egovernment adoption, the concept should have been looked at from User characteristics (perceived risk, perceived control, and internet), Website design (perceived usefulness, perceived ease of use), Service quality and Client satisfaction perspectives [9]. Indeed there were other frameworks and models developed in the area of e-government services however most of these frameworks we either for evaluating the impact of e-government services or for assessing its implementation. [10]

\subsection{Technology Roadmaps}

A roadmap is a guiding structure that facilitates the execution of a set of pre-defined high-level activities that are deemed necessary to achieve specific objectives [11]. In relation to this study, the adoption of e-payments involves execution of predefined high-level activities to achieve effective end-toend adoption in government. It identifies all aspects that need to be addressed prior, during and after technology implementation [12], [38]. In other words an e-payments roadmap is a carefully planned reform of government payment programs that can have far-reaching consequences on the modernization of the national payments systems. Most technology adoption roadmaps do not consider the operational environment and mapping of the business case to the roadmap while at the same time taking care of the human factor [13]. Roadmaps should be mechanisms that enable organizations to visualize their critical assets, the relationships between stakeholders, technology and skills required for future and current market demands [1]. The traditional software development methodologies and IT project management standards placed more emphasis on technological perspective and project management technical issues [14]. Instead, they should also consider social dynamic issues like change management, awareness, perception and stakeholder involvement [15]. This does not imply that these models as roadmaps for systems development and adoption were inadequate; they just came short of addressing the human issues effectively. Even Agile Software Development that is a relatively different approach to IT projects management from classical systems development methodologies fell short of addressing `adoption issues [15]. Although it placed more emphasis on individuals and how they relate other than on processes and tools, it is however centered on development and not on implementation and adoption [16], [12]. For any technology adoption roadmap to be effective, it must include
Stakeholder engagement, Change management, ICT infrastructure, conducting of awareness and Compliance to regulatory frameworks [17].

\subsection{Information Technology Adoption Models}

As a technology adoption concept, the e-payments adoption roadmap in this research was derived from the integration of Technology Organization Environment (TOE) and Technology Acceptance Model (TAM) [18], [12], [46] with enhancement from risk perception model [17]. The TOE model identifies three aspects of an enterprise's context that influence the process by which it adopts and implements a technological innovation: Technological context, Organizational context, and Environmental context [19]. The TOE theory does not address the human behavioral aspects in systems adoption but it is very solid on addressing technical and environmental issues. TAM proposes perceived usefulness (PU) and perceived ease of use (PEOU) as the fundamental determinants of IT adoption. An individual's intention to use a system is explained and predicted by his perception of the technology's usefulness and its simplicity. In the case of e-payment systems in government, it is the government employees' perception either as individuals or as the whole entity towards the concept that should be addressed through change management and awareness. As much as these models address both the technical and human issues, they do not sufficiently address the issue of change management, stakeholder engagement and other none technical perceptions like information security and risk.

\subsection{Conceptual Framework}

The proposed framework in this study took into account the importance of technical, environment, organizational and perception. It also emphasized the important role played by human factors like change management, stakeholder engagement, information security concerns and awareness as depicted in the diagram below. The framework proposed that stakeholder engagement should be done when dealing with the identified issues affecting e-payments adoption in the government of Kenya. In this model, Technology is addressed under ICT infrastructure and awareness, Environment is integrated to ICT Infrastructure and Stakeholder engagement. Organization covered broadly under stakeholder engagement, awareness and Change Management. This model extended the integrated Model of TAM and TOE by including security and risk aspects [19].

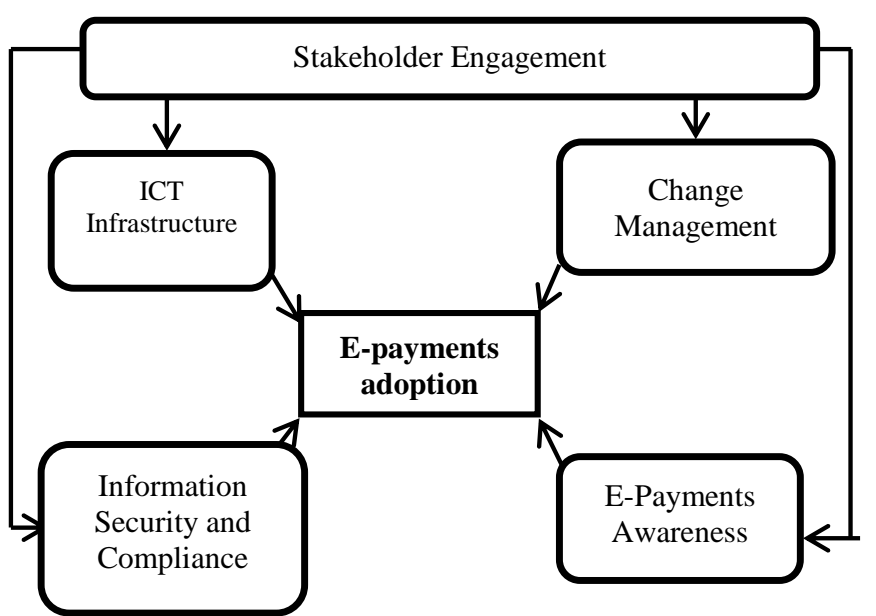

Figure 1: Conceptual Framework 
Stakeholder engagement in this model is the process of involving those groups, people or entities who affect and/or could be affected by the government's e-payments initiative [20]. In order to achieve successful adoption of e-payments in government, this Model proposed that stake holder engagement should be effected at each level of the government of Kenya's e-payments initiative. In this Model, ICT Infrastructure refers to the technologies or the composite hardware, software, network resources and services required for the existence, operation and management of government e-payments environment. ICT Infrastructure allows the government to deliver e-payments services to its citizens. This Model identified Change management as critical aspect of adoption of e-payments in the government of Kenya. Change Management provides guidance on how the government will prepare, equip and support individuals to successfully adopt the change from manual and legacy systems to e-payments and realize the benefits. The model proposed that awareness has to be done within Kenyan government MDA's to develop the knowledge and understanding about government epayments and communicate its benefit. Awareness equips stake holders with adequate and right information about government e-payments thus enhancing MDA's trust. This hastens adoption of e-payments [13]. Perceived risk and perceived behavioral control is defined as fear of losing personal information and fear of being monitored on electronic platforms [21]. In the proposed model the risk perceptions over information is addressed through information security and compliance. If MDA's and their employees had control over how personal information is going to be used, and the control of how and when information can be acquired, adoption of e-payments will be easier and faster[49].

\section{RESEARCH METHODOLOGY}

In this study, a descriptive survey research design was used. A descriptive research design was used because the research problem was well understood and structured [22]. Descriptive research design provided a complete description of the case under study without bias [22]. This study was majorly quantitative by providing the data that was required to determine how identified issues impact on adoption of e-payments in government of Kenya and establish among the identified issues in the objectives of this study the one that has a greater impact on the adoption of e-payments. The research was conducted to explore the adoption of government epayments in Kenya and determine how ICT Infrastructure, Awareness, Change management and Information security impact on e-payments adoption. This approach enabled the researcher to examine the data within the specified context of the research scope. This method was used because it was useful in describing the characteristics of widely dispersed government entities on e-payments and ensured a more accurate sample to gather targeted results in which conclusions were drawn. It also offered many modes in which it could be administered offering options for cost effectively reaching out to target population in remote areas [22]. In this case, an online questionnaire was used. Descriptive survey research enabled the researcher to explore e-payments in the government of Kenya with samples that accurately represented the population, about whom generalizations were made [21], [22]. The survey study provided an avenue for more honest and unambiguous responses due to the fact that it gave respondents the option of remaining anonymous.

\subsection{Target Population and Sample Size}

Target population is generally a large collection of individuals or objects that are the focus of a scientific query [22]. It is the total group of individuals from which the sample might be drawn. This research targeted heads of information communication technology (ICT) and Finance in 19 government Ministries, 262 state corporations and 47 counties. The selected respondents were involved in shaping the direction of automation of business processes and finance management in their respective government offices in Kenya.

In this study, the population was stratified before sampling. There were three primary strata in the design. The groups included IT professionals and Finance professionals from Ministries, Counties, and State Corporations. This method was preferred as each of this groups represent different interests in government thus members of each group had an equal chance of being selected in this research study.

Having known the population size, the sample size was determined by first determining the sample size of each subgroup through application of the following formulae [28], [26], [27];-

$$
\mathrm{N}=\frac{\mathrm{N}}{\mathrm{N}+\mathrm{N}(e)^{2}}
$$

Where $\mathrm{n}=$ sample size, $\mathrm{N}=$ the population size. $\mathrm{e}=$ Level of precision.

Table 1: Sample size (Author 2016)

\begin{tabular}{|l|l|l|}
\hline CATEGORY & $\begin{array}{l}\text { POPULATION } \\
\text { FREQUNCY }\end{array}$ & SAMPLE SIZE \\
\hline Ministries & 19 & 18 \\
\hline Counties & 47 & 41 \\
\hline State Corporations & 265 & 181 \\
\hline TOTAL & $\mathbf{3 3 1}$ & $\mathbf{2 4 0}$ \\
\hline
\end{tabular}

\subsection{Study Variables}

Dependent variables

i. e-payments adoption

Independent variables

$\begin{aligned} \text { i. } & \text { ICT infrastructure } \\ \text { ii. } & \text { Awareness of government e-payments } \\ \text { iii. } & \text { Information security and Compliance } \\ \text { iv. } & \text { Change management } \\ \text { v. } & \text { Stakeholder engagement }\end{aligned}$

\subsection{Data Collection Tools and Method}

An online questionnaire was developed and administered to the respondents. E-mail addresses of the respondents were acquired from various government professional groups like the ICT caucus for vision 2030 and from the Treasury for Heads of finance. Sampled members were sent an e-mail that described the study and provided the URL for a web survey. A reminder was sent via e-mail to the respondents approximately at an interval of 2 days for a period of 3 weeks. The online portal remained open for a period of 3 weeks. The researcher used web administered questionnaires by survey monkey to ensure efficiency, cost effectiveness and that the questionnaires were administered to respondents in the same way and format [22]. The use of questionnaires was selected to collect both qualitative and quantitative data. The questions were both closed and open-ended. The closed ended questions had multiple choices with scales from which the respondents 
could choose from options given. This ensured accurate uniform collection of quantitave data. Open ended questions were used to collect data by providing the respondents with an opportunity to give their independent views about the subject matter without being limited unlike in the closed questions. In general, the questionnaire sought to determine if the available government e-payments frameworks are adequate and determine how lack of adequate ICT infrastructure, e-payment awareness, change management, stakeholder engagement and information security concerns affect the adoption of epayments in the government of Kenya. Each question was designed to address the objectives and research questions in this study [8]. The questionnaire was segmented into five sections each addressing each research variable.

\subsection{Reliability and Validity}

Reliability is a measure of the degree to which a research instrument yields consistent results or data after repeated trials [22]. Validity is the degree to which results obtained from the analysis of the data actually represent the phenomenon under study [22]. Reliability was ensured in the data collected through carefully selecting the sample in order to avoid bias. The questionnaire was subjected to peer reviews and scrutiny from subject area experts. A pilot study was conducted to verify reliability of the online questionnaire and relevant adjustment were done accordingly. Cronbach's alpha index [23] was used to assess the internal consistency (average correlation) of items in the online questionnaire thus gauging its reliability. Unlike Test-Retest and Split halves methods of testing reliability that required repeating of the test or splitting the test sample, Cronbach's alpha required a single administration of the test to yield a unique estimate of reliability [29]. Some questions were designed to provide more information about the subject under investigation and ensured determination of consistency in the responses given.

\subsection{Reliability Test}

For a study to be more reliable, the Alpha values have to be above 0.6 [29]. Using SPSS, the Cronbach Alpha [23] for this study was 0.758 .

\subsection{Validity Analysis}

Data collected from responses to the online questionnaire was coded for processing. After receiving the responses, the questionnaires were checked for completeness and consistency. The data was then systematically organized to enable analysis. The collected data was qualitatively and quantitatively analyzed. For quantitative analysis, the number of responses per question for or against an assertion made was done. The survey findings have been validated by statistical analysis models such as regression analysis, correlation analysis and analysis of variance using Statistical Package for Social Sciences (SPSS).

\section{RESULTS AND DISCUSSION}

As illustrated in the table below, the target population for the survey was 240 respondents. However, the researcher could only find the contacts of 183 possible respondents. This represented $78 \%$ of the target sample population. A $68 \%$ response rate was achieved. A response rate above $50 \%$ is acceptable in descriptive research [30].
Table 2: Response Rate

\begin{tabular}{|l|l|l|l|l|}
\hline $\begin{array}{l}\text { Population } \\
\text { size }\end{array}$ & $\begin{array}{l}\text { Target } \\
\text { Sample } \\
\text { size }\end{array}$ & $\begin{array}{l}\text { Accessed } \\
\text { Sample } \\
\text { Size }\end{array}$ & $\begin{array}{l}\text { Number } \\
\text { of } \\
\text { Responses }\end{array}$ & $\begin{array}{l}\text { Response } \\
\text { Rate }\end{array}$ \\
\hline 331 & 240 & 183 & 123 & $68 \%$ \\
\hline
\end{tabular}

Data gathered from this survey shows that $76 \%$ of government MDA's receive payments for the services rendered. $73 \%$ of these organizations receive cash payments as well as other automated forms of payments as indicated in figure 2 below

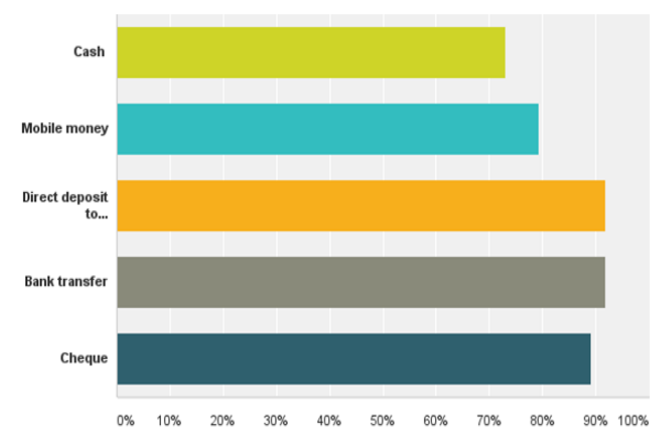

Figure 2: Payment Methods in the Government of Kenya

Generally data obtained from questionnaires revealed the following findings about the variables under study.

\subsection{ICT Infrastructure}

This survey revealed that $73 \%$ of MDA's in Kenya process payments both manually and using computerized systems. Only $21 \%$ had fully automated their payments processes. $50 \%$ of the staff working in the payments offices had full access to internet throughout the day. However, $43 \%$ of the respondents indicated that internet connectivity was not reliable. Even though there is some form of access to network infrastructure, $52 \%$ of payments processing staff did not have the necessary software tools to process payments. $48 \%$ of the respondents found it is difficult to reconcile their payments accounts and generate adequate reliable financial reports. Most of the respondent believed that implementation of government e-payment system was complex and difficult. It was also found that $60 \%$ of government organizations lacked the necessary skills to implement and support e-payment systems.

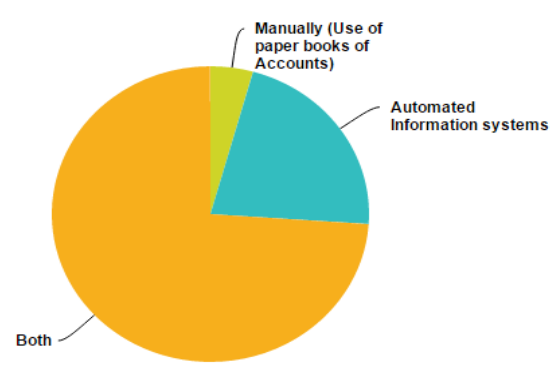

Figure 3 Methods of Payment processing systems

\subsection{E-Payments Awareness}

In Kenya, most of the MDA's staff understood what e-payments are. However, there were no standard guidelines and procedures on adoption of government e-payments. 
From the survey, over $80 \%$ of the respondents indicated that there were no procedures and guidelines on adoption of government e-payments. Furthermore, $68 \%$ of MDA's did not know which government organization(s) was mandated with implementing e-payments. Even those who indicated that they were aware of government entity charged with implementing and managing government e-payment system, over $50 \%$ could not point out to a specific organization. This lack of adequate information on e-payments within government MDA's has resulted in a lot of misconception about e-payments. For instance, it was found that $54 \%$ of the respondents believe that government e-payment was insecure. 0ver 30\% holds it that e-payments will deny them controls of the revenue collected and will lead to loss of jobs. There was also another misconception that deployment and adoption of e-payments in government was a very complex undertaking.

\subsection{Change Management and Stake Holder Engagement.}

The survey study revealed that change management on adoption of e-payments in Kenyan government was a major factor. $61 \%$ of the respondents were in agreement of the assertion that lack of a change management strategy was a hindrance to the adoption of e-payments in government. Furthermore, $88 \%$ of the respondents did not understand the procedure to follow on adopting government e-payments and the stakeholders to engage.

\subsection{Information Security and Compliance}

Table 3 shows the Specific Concerns on information security with adoption of E-payments.

Table 3: Response to specific information security concerns

\begin{tabular}{c|cc}
\hline Lack of information control & $52.33 \%$ & 45 \\
\hline$\quad$ Insufficient security controls & $87.21 \%$ & 75 \\
\hline$\quad$ Data lose with system failures & $82.56 \%$ & 71 \\
\hline$\quad$ Legal compliance issue & $48.84 \%$ & 42 \\
\hline L Legal data ownership issues & $45.35 \%$ & 39 \\
\hline
\end{tabular}

\subsection{Statistical Analysis}

\subsubsection{Correlation Analysis}

The findings of this study were subjected to a correlation analysis to determine whether any relationship exited between the dependent variable (adoption of e-payment system) and the independent variables (adequacy of ICT infrastructures, awareness of e-payment system, e-payment security, and compliance, change management, and Stake holder engagement). Correlation findings are indicated in Table 4.

Table 4: Correlation Matrix

\begin{tabular}{|c|c|c|c|c|c|c|c|}
\hline Statements & & 1 & 2 & 3 & 4 & 5 & 6 \\
\hline \multirow{2}{*}{$\begin{array}{l}\text { Adoption of e-payment } \\
\text { system }\end{array}$} & Pearson's Correlation & 1 & & & & & \\
\hline & Sig (2 tailed) & 0.001 & & & & & \\
\hline \multirow{2}{*}{$\begin{array}{l}\text { Adequacy of ICT } \\
\text { infrastructure }\end{array}$} & Pearson's Correlation & $.636^{* *}$ & .391 & 1 & & & \\
\hline & Sig (2 tailed) & .001 & .056 & & & & \\
\hline \multirow{2}{*}{$\begin{array}{l}\text { Awareness of } \\
\text { payment system }\end{array}$} & Pearson's Correlation & $.575^{*}$ & $.432^{* *}$ & $.338^{*}$ & 1 & & \\
\hline & Sig (2 tailed) & .002 & .020 & .040 & & & \\
\hline \multirow{2}{*}{$\begin{array}{l}\text { E-payment security and } \\
\text { compliance }\end{array}$} & Pearson's Correlation & $.702^{* *}$ & $.462^{* *}$ & .330 & .314 & 1 & \\
\hline & Sig (2 tailed) & .020 & .028 & 0.030 & 0.050 & & \\
\hline \multirow[t]{2}{*}{ Change Management } & Pearson's Correlation & $.482^{* *}$ & $.406^{*}$ & .396 & .347 & .133 & 1 \\
\hline & Sig (2 tailed) & .000 & .040 & .050 & .102 & .122 & \\
\hline \multirow[t]{2}{*}{ Stakeholder Engagement } & Pearson's Correlation & $623 * *$ & $605^{*}$ & 558 & 552 & 550 & 640 \\
\hline & Sig (2 tailed0 & .000 & .000 & .000 & .020 & .030 & .000 \\
\hline
\end{tabular}

**. Correlation is significant at the 0.01 level (2tailed).

*. Correlation is significant at the 0.05 level (2-tailed).

According to the study findings, the relationship between adoption of e-payment system and the adequacy of ICT infrastructure was strong, positive and significant; $r$ (0.636); $\mathrm{p} \leq 0.05$. This was followed by a strong positive relationship between adoption of e-payment system and the awareness of e-payment system; $\mathrm{r}(0.575) ; \mathrm{p} \leq 0.05$. This was followed by a strong positive relationship between implementation of e-payment system and E-payment security and compliance; $r$

$(0.702) ; p \leq 0.05$. The relationship between adoption of epayment system and change management was equally positive; $\mathrm{r}(0.482) ; \mathrm{p} \leq 0.05$, therefore significant. The relationship between adoption of e-payment system and stakeholder engagement was positive; $r(0.623) ; p \leq 0.05$, therefore significant. Adequacy of ICT infrastructure had a significant relationship with other independent variables as follows: Awareness of e-payment system; $r(0.433) ; p \leq 0.05$, 
E-payment security and compliance; E-payment security and compliance; $\mathrm{r}(0.462) ; \mathrm{p} \leq 0.05$, Change Management; $\mathrm{r}$ (0.402); $\mathrm{p} \leq 0.050$; stakeholder engagement; $\mathrm{r}(0.605) ; \mathrm{p} \leq$ 0.05 .

\subsubsection{Multiple Regression Analysis}

The study variables were subjected to regression analysis to determine the level of significance. The findings are presented in Table 5, below. The regression model used was
$\mathrm{Y}=$ $\beta_{0}+\mathrm{B}_{1} \mathrm{X}_{1}+\beta_{2} \mathrm{X}_{2}+\beta_{3} \mathrm{X}_{3}+\beta_{4} \mathrm{X}_{4}+\beta_{5} \mathrm{X}_{5} e ;$ Where $X_{1}=$ Adequacy of ICT infrastructure; $X_{2}=$ Awareness of e-payment system; $\mathrm{X}_{3}=$ E-payment security and Compliance; $\mathbf{X}_{\mathbf{4}}=$ Change Management; $\mathbf{X}_{\mathbf{5}}=$ Stakeholder engagement.

Table 5: Model Summary of Multiple Regressions

\begin{tabular}{|l|r|r|r|r|}
\hline Model & \multicolumn{1}{|c|}{$R$} & $R$ Square & Adjusted $R$ Square & Std. Error of the Estimate \\
\hline 1 & $.929^{a}$ & .864 & .824 & .301 \\
\hline
\end{tabular}

a. Predictors: (Constant), Adequacy of ICT infrastructure, Awareness of e-payment system, E-payment security and Compliance, Change Management, Stakeholder engagement

According to the findings in Table 5, multiple regressions indicates an adjusted $\mathrm{R}$ squared of 0.764 implying that $82.4 \%$ of variation in adoption of e-payment system was attributable to adequacy of ICT infrastructure, Awareness of e-payment system, E-payment security and Compliance, Change
Management. $18.6 \%$ of variation in adoption of e-payment system was covered with other factors not considered in this study.

Analysis of Variance (ANOVA)

Table 6: Analysis of Variance

\begin{tabular}{|ll|r|r|r|r|r|}
\hline Model & Sum of Squares & df & Mean Square & F & Sig. \\
\hline \multirow{3}{*}{1} & Regression & 14.798 & 5 & 1.533 & 16.873 & \\
& Residual & 3.544 & 119 & .091 & \\
& Total & 14.342 & 124 & & & \\
& & & & \\
\hline
\end{tabular}

a. Dependent Variable: adoption of e-payment system

b. adequacy of ICT infrastructure, Awareness of e-payment system, E-payment security and Compliance, Change Management, Stakeholder engagement.

According to Table 6, the variation between the groups sum of squares was 14.798; with degree of freedom df (4); $\mathrm{F}(5,119)=16.873 ; \mathrm{P}<0.00<0.05 ;$ therefore there was significant relationship between adoption of e-payment system and adequacy of ICT infrastructure, awareness of e-payment system, E-payment security and compliance and change management.

Regression Coefficients

Table 7: Regression Coefficients

\begin{tabular}{|l|r|r|r|r|r|}
\hline \multirow{2}{*}{ Model } & \multicolumn{2}{|c|}{ Unstandardized Coefficients } & \multicolumn{2}{c|}{$\begin{array}{c}\text { Standardized } \\
\text { Coefficients }\end{array}$} & \multirow{2}{*}{ Sig. } \\
\cline { 2 - 5 } & B & Std. Error & Beta & \\
\hline (Constant) & 1.600 & 3.271 & .389 & .000 \\
Adequacy of ICT infrastructure & .966 & .337 & .669 & 3.570 & .016 \\
Awareness of e-payment system & .052 & .227 & .341 & -.357 & .000 \\
E-payment security and compliance & .768 & .399 & .456 & 1.651 & .025 \\
Change management & .149 & .110 & .278 & -1.790 & .070 \\
Stakeholder engagement & .312 & .226 & .215 & 1.602 & .000 \\
\hline
\end{tabular}

The findings in Table 7 indicates a regression coefficient $B$ (0.669); $P<0.05$, between adoption of e-payment system and adequacy of ICT infrastructure. The relationship between adoption of e-payment system and awareness of e-payment system had a regression coefficient $\beta(0$. 341); $\mathrm{P} \leq 0.05$, therefore significant. The relationship between adoption of e-payment system and e-payment security and compliance had a regression coefficient $B(0.456) ; \mathrm{P} \leq 0.05$, therefore significant. The relationship between adoption of e-payment system and change management had regression coefficient $\beta$ 
(0. 278); $\mathrm{P} \geq 0.05$, therefore the relationship was not significant. The relationship between adoption of e-payment system and stakeholder engagement had a regression coefficient $\beta(0.215) ; \mathrm{P} \leq 0.05$, therefore significant.

The formula used to compute the relationship was;

Adoption of e-payment $=1.600+0.966 \mathrm{X}_{1}+0.052 \mathrm{X}_{2}+$ $0.768 \mathrm{X}_{3}+0.149 \mathrm{X}_{4}+0.315 \mathrm{X}_{5}$

Where $\mathbf{X}_{1}=$ Adequacy of ICT infrastructure. $\mathbf{X}_{\mathbf{2}}=$ Awareness of e-payment system $\mathbf{X}_{\mathbf{3}}=$ E-payment security and Compliance, $\mathbf{X}_{\mathbf{4}}=$ Change Management, $\mathrm{X} 5=$ Stakeholder engagement.

\section{CONCLUSION RECOMMENDATIONS AND FURTHER WORK}

This study analyzed e-payments in the government of Kenya by evaluating the existing frameworks and examined the identified issues and how they impact on its adoption. The absence of an adequate guideline through which Change management, Stakeholder engagement, ICT infrastructure, awareness and Information security and compliance was found to have a big impact the adoption of e-payments in the government of Kenya.

\subsection{Study Achievements}

From the study, it was determined that there was no clearly defined roadmap to guide government Agencies on how to adopt e-payments. The study further revealed that there was lack of sufficient information on government e-payments that had led to misconceptions and wrong perceptions about government e-payments resulting to outright resistance and negative attitude towards e-payments adoption within government MDAs. The study concluded that Information Security and Compliance, ICT Infrastructure, Change Management, Awareness, and Stakeholder engagement were the main issues affecting e-payments adoption in the government of Kenya and that these issues should be addressed through a consolidated guideline like a Roadmap. The study established that although there were several frameworks on Kenya's e-citizen to which e-payments are a sub section, there was none that addresses e-payments specifically.

In the study, the first objective was to establish the reasons for slow adoption of e-payments in the government of Kenya.

It was found that the absence of a clear guideline on adoption of e-payments had resulted to its slow adoption. This guideline should have addressed issues affecting the adoption of e-payments in the government of Kenya. Key issues affecting the adoption of e-payments in the government of Kenya were identified as change management, Stake holder engagement, ICT infrastructure, e-payments awareness and information security and compliance.

The second objective of the study was to evaluate the existing frameworks on e-payments in Kenya. The study found that the frameworks that exist were either for e-citizen in general or e-government frameworks. Even though government e-payments fall within e-government or e-citizen realm, the study found that there was insufficient information on e-payments adoption models in the government of Kenya. On the Framework for quality assessment of e-government Service Delivery in Kenya, there has to be strong political support, coherent Information infrastructure and change management [30]. The frameworks reviewed in the literature of this study were either for assessment of e-government services or General Roadmaps and Master plans for government ICT. Most of the existing models and frameworks were found either to be for evaluation of the impact of e-citizen or assessment of the success of e-citizen in Kenya. An example of this is the framework for Evaluating the Impact of e-Government from citizen's perspective [10]

The third objective of this study which forms the core of this research was to develop a roadmap for adoption of e-payments for the government of Kenya. This roadmap was to address issues that have been identified to be impairing the adoption of e-payments in the government of Kenya. From the analysis of the results of the study, it was evident that Stakeholder engagement, Change Management, ICT infrastructure, e-payments awareness and Information security and compliance were the key issues affecting the adoption of e-payments in the government of Kenya. From this study the following model was proposed as a Roadmap for the adoption of e-payments in the government of Kenya.

Information Security and Compliance: The study found that Information security and compliance had a high relationship with adoption of e-payment systems in the government of Kenya. From the study, it was concluded that some of the misconceptions about government e-payments were as result of the perceived insecurity of the existing e-payments platforms. In as much as security is not usually an issue for customers who intend to use government e-payment it was found to be an issue of concern for government respondents who took part in this study. Most government officials lacked understanding of information security on electronic transactions. There was little regard for information security and compliance within government to the extent that no security and business continuity strategies and plans had been put in place. A legal framework for payments encompassing electronic payments existed though compliance to the National payment systems act [7] was still a major issue to most MDA's. From the study it was established that the following information security and compliance issues should be addressed by the guideline for adoption of government e-payments in Kenya.

a) Establish regulatory frameworks for government e-payments

b) Develop government E-payments information security policy.

c) Determine and communicate Risks.

d) Define alternative technology pathways to overcome barriers to adoption of e-payments.

e) Develop government e-payments standards.

ICT Infrastructure: This study concluded that adequacy of ICT infrastructure was a major issue on adoption of government e-payments in Kenya. To this regard, adequate ICT infrastructure contributes significantly to adoption of epayment systems. In as much as internet penetration in Kenya was among the highest in Africa, Some Kenyan government offices still face unreliable internet connectivity challenges.

The government e-payments platforms that existed, had most of activities conducted online hence too much dependence on the internet. The study also found that there was inadequate skill to implement and support e-payments in MDA's in the Government of Kenya. Customer side infrastructure for access to the government e-payment services was found not to be an issue of great concern. This was attributed to the fact that Kenya has the basic infrastructure to support e-payments through the mobile telecommunication infrastructure and 
Banks retail POS devices at shops and village Kiosks. There were also challenges with integration of the various financial systems in government agencies to the envisaged government e-payment system that will facilitate government e-payments. The study concluded that infrastructure issues hampering adoption of e-payments should be enshrined in the roadmap for adoption of e-payments in the government of Kenya as follows [17], [34]

a) Determine Infrastructure requirements for government e-payments in Kenya

b) Establish or determine the organization to Manage government e-payments gateway

c) Design the architecture of Kenya government e-payments system

d) Implement government e-payments system.

e) Continuous Update of the system in relation to the dynamics of business environment

For sustainability of government e-payments infrastructure, a business sustainability model should be developed [31].

Change Management: This study concluded that indeed change management was a major issue in adoption of government e-payments. Although cashless payments have picked up in Kenyan society, it was found that Government Agencies were yet to exploit these platforms, which include Mobile money, Banks POS terminals in shops and Village Kiosks, credit cards, and debit cards. Government MDA's were still receiving payment made by cash. Even where automation has been done, mixtures of modes of payments were still being used which made it difficult to reconcile various government accounts and provide accurate financial reporting to the exchequer. This was attributed to unwillingness to change as revealed by the study. Some government employees preferred cash payments over electronic payments partly because transition benefits to cashless payments have never been communicated. To compound this problem, the study found that structures in finance departments in government offices supported cash payments as most of them had cash offices manned by cashiers. There was no guideline by the government to provide a standard procedure of adopting e-payments by integrating existing payment processing systems to the government payment gateway. Majority of the MDA's do not know the stakeholders to engage in their quest to adopt e-payments. The study also found that there was confusion about which Government Agency was mandated to manage the e-payment system and which one regulated government e-payments. In this study it was revealed that social cultural issues of the population were also an impediment to be dealt with due to literacy levels. A large part of the population was still unbanked despite government efforts to open up the financial services sector by allowing mobile telecommunication companies to operate mobile bank accounts. Change management issues can be addressed in an integrated guideline like a Roadmap [17]. The Roadmap should seek to address the issues of change management by performing the following tasks.

a) Establish Steering Committee

b) Develop Change Management Strategy

c) Determine the level of change (What is going to be done differently)

d) Determine advocates and early adopters of the system

e) Determine MDA's that might present the most resistance and why) f) Select change management champions.

g) Communicate the change and benefits

h) Manage transition and realization of benefits

Awareness of e-payment systems was found to be one of the contributing factors to its slow adoption in the government of Kenya. This study indicated that most government employees in ICT and Finance department did not understand what an e-payment was. There was a negative perception towards adoption of e-payments. Government employees did not view e-payments as a tool to simplify their work. The misconception was that e-payments will render some of them jobless. The thinking within MDA's was that by adopting e-payments, they were to lose control of revenues they collected. The study found that Government e-payments in Kenya were perceived to be complex and difficult to implement. To address these issues of e-payments awareness, the following should be addressed in the formulation of adoption Roadmap [34].

a) Develop an awareness program

b) Conduct expert workshops

c) Communicate the Benefits of Government e-payments

d) Determine knowledge gaps.

e) Customize different messages for different groups

f) Sustained awareness and training activities

\section{Stakeholder Engagement:}

From the study, it was concluded that Stakeholder engagement affects the adoption of e-payments in the government of Kenya. This study indicated that the concept of stakeholder engagement was still confusing. Most government officials think that as long as they have invited few government agencies and department to their meetings, then that constituted stakeholder engagement. However, for enhancing the development and adoption of e-payment systems, it is essential that the private sector, the civil society, private citizens and ICT experts be all involved early enough in government technology Roadmapping to enable easy buy in [41]. Equally, the stakeholder meeting need to be consultative, where the government doesn't just give information, but actively seek information and input from this stakeholders. For stake holders to be engaged in a structured and effective manner in technology Roadmapping the following must be done [17]:-

a) Top leadership Support -i.e. the Executive and the Legislative arms of government (In the case of Kenya).

b) Determine entities that will be affected by the system and engage

c) Gather Consensus From cross section Experts (Public policy, economics and Social Science)

d) Identify Key technical and Institutional Barriers.

e) Create reviews and consultation cycles.

f) Establish a communication strategy

The study indicated that Stake holders should be engaged throughout the cycle of the project for the adoption to be successful. 


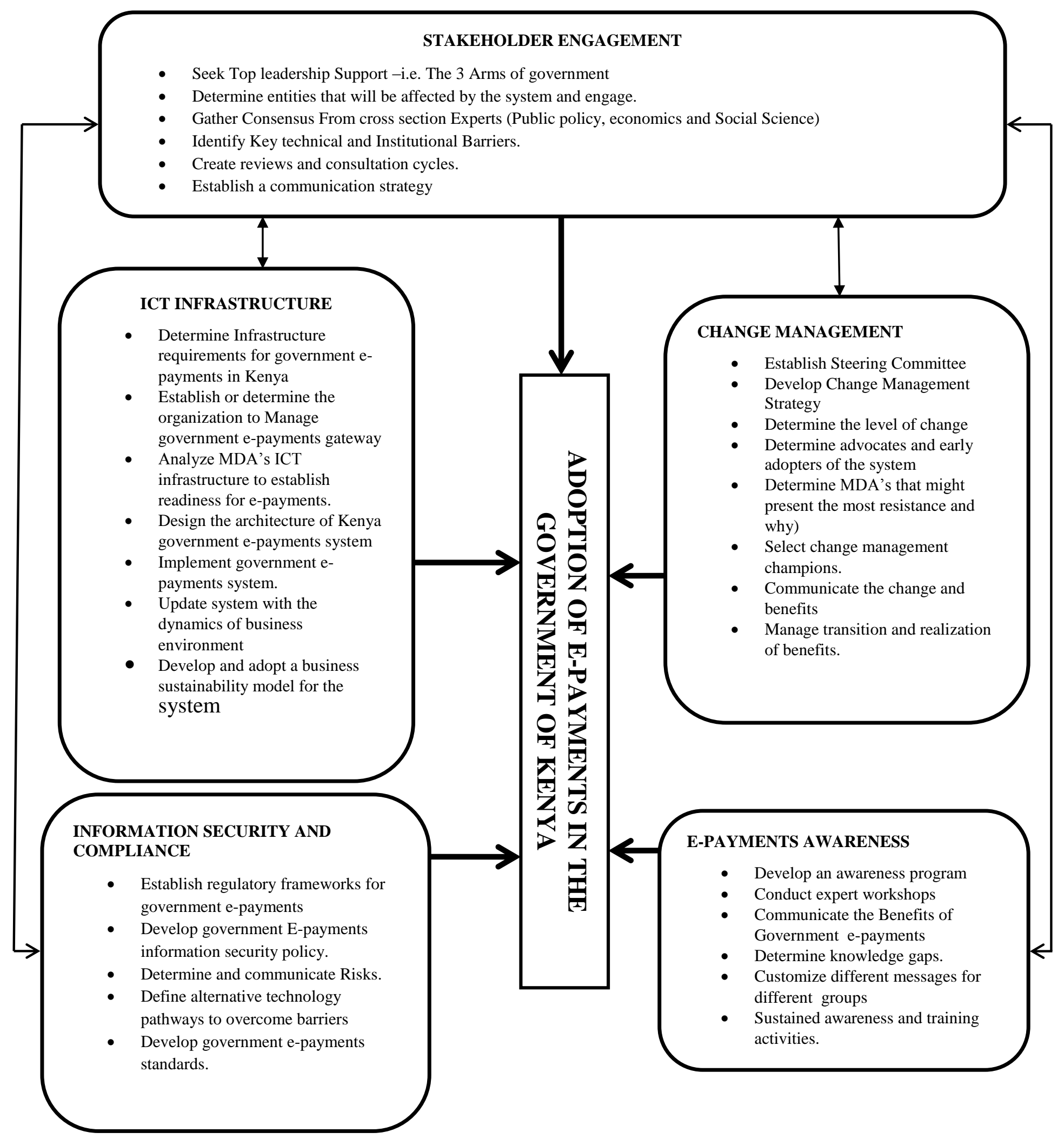

Figure 4: Model E-payments Roadmap for the government of Kenya

\subsection{Recommendations and Further Research}

This study shows that there are issues that need to be addressed for e-payments to be fully adopted in the Kenyan government. The proposed roadmap in this study should be adopted to act as a universal guide to identify all aspects that need to be addressed prior, during and after e-payments implementation and adoption [3]. The government of Kenya needs to adopt this roadmap that maximizes participants' engagement in developing national e-payments requirements, execution plan, change management, awareness and security thereby building consensus and increasing the likelihood that the system will be successfully adopted. 
Further research may delve into adoption and use of government e-payments from the public perspective and evaluation of the effectiveness of government e-payments. Also further research could be done on models of integration of the autonomous MDA's finance management systems to centralized government e-payment platforms. Other future studies could be done as a comparative analysis of Kenya's government e-payment systems with other developed world.

\section{ACKNOWLEDGMENTS}

The author would like to thank the entire school of computing and Informatics at the university of Nairobi, in particular My Co-author Prof. Elijah Omwenga for the guidance during this research. Tribute also goes to my lovely wife Synthiah Ijayo for her support.

\section{REFERENCES}

[1] David Smith (2005) "Strategic Roadmap" Technology Futures Inc. Texas USA. Available Online at http://tfi.com

[2] Izhar, Ailya; Khan, Aihab; Khiyal, Malik Sikandar Hayat; Javed, Wajeeh; Baig, Shiraz. (2011) "Designing and Implementation of Electronic payment Gateway for Developing countries" Journal of Theoretical \& Applied Information Technology. 2011, Vol. 26 Issue 2, p84-90. $7 \mathrm{p}$ vol. 26

[3] Upendra Nambur (2011) Electronic Payments in India Looking Back \& Surging Forward: Available at: www.pymnts.com

[4] Wondwossen T., Tsegaye G., Solomon A. and Dawit B. (2006). E-Payment in Ethiopia: Challenges and Opportunities" Forum on ICTs, Trade and Economic Growth. March $14-16,2006$

[5] Karamjeet Kaur1 and Ashutosh Pathak, (2015). EPayment System on E-Commerce in India. Available at: https://www.ijera.com

[6] Haruna, I. (2012). Challenges of Electronic Payment Systems in Ghana: The Case of e-ZWICH. American Journal of Business and Management, 1(3), 87-95

[7] National Council for Law Reporting (2011), National Payment systems act. Available at www.kenyalaw.orgInter- American Center of Tax administrations 48th general assembly

[8] Legris, Paul, Collerette and Pierre: A Roadmap for IT Project Implementation - Integrating Stakeholders and Change Management Issues; in: Project Management Journal, Vol. 27 (2006), No. 5, pp. 64-75

[9] Kumar V, Mukherjee B, Butt I \& Persuade A (2007) "Factors for Successful E-Government Adoption: a Conceptual Framework" The Electronic Journal of eGovernment Vol. 5, No, 1, pp 63 -76, available online at www.ejeg.com

[10] Otieno I. and Omwenga E. (2014). Towards the Development of a Citizen-Centric Framework for Evaluating the Impact of e-Government: A Case Study of Developing Countries

[11] Abdoulmohammad G. Chofreh, Feybi A. Goni, Awaluddin M. Shaharoun and Syuhaida Ismail (2015) "A Review on Sustainability Transformation: Roadmaps using Project Management Methodology" . Available at https://www.researchgate.net/publication
[12] Lee Badger, Robert Bohn, Shilong Chu and Mike Hogan (2011) "US Government Cloud Computing Technology Roadmap" Volume II Release 1.0 Useful Information for Cloud Adopters. National Institute of Standards and Technology (NIST)

[13] Davis, F. (1993) User acceptance of information technology: System characteristics, user perceptions and behavior impacts. International Journal of Man-Machine Studies,

[14] Carmines, E. G. and Zeller, R. A. (1979). Reliability and validity assessment. Thousand Oaks, CA: Sage

[15] David Miller and Mike Oliver (2015) "Engaging stakeholders for project success" Available at:https://www.pmi.org/ /media

[16] Rashmi P. Anita and Naresh C (2013) “A mapping model for transforming traditional software development methods to agile methodology". International Journal of Software Engineering \& Applications (IJSEA), Vol.4, No.4, July 2013

[17] International Energy Agency (IEA) (2014) "Energy Technology Roadmaps" A guide to development and implementation. Available at http://www.iea.org/publications/freepublications/publicat ion/TechnologyRoadmapAguide to development and implementation.pdf

[18] Hart O. and Ojiabo U. (2012) "Integrating TAM and TOE Frameworks and Expanding their Characteristic Constructs for E-Commerce Adoption by SMEs". Proceedings of Informing Science and IT Education Conference (InSITE).

[19] Muhammad Sajjad, Asad Afzal Humayoun and Ziaullah Khan (2010),"Risk perception And adoption of technology": An empirical study of personal computer use for Pakistani managers. "African Journal of Business Management Vol. 4(14), pp. 3080-3086, 18 October, 2010 available online at: http://www. Academic journals.org/AJBM"

[20] Choudrie J. and Dwivedi Y.K. (2005), The Demographics of Broadband Residential Consumers of a British Local Community: The London Borough of Hillingdon, Journal of Computer Information Systems, Vol. 45, NO. 4, pp. 93101

[21] Dillman Don. (2000). Mail and Internet Surveys: The Tailored Design Method. New York: John Wiley \& Sons, Inc.

[22] Mugenda O. and Mugenda, A. (2003) Research Methods. Acts Press, Nairobi

[23] Cronbach, L. J. (1951). Coefficient alpha and the internal structure of tests. Psychometrical. 16, 297-334

[24] Mumford and Henshall, (1979) The rise and decline of the ETHICS methodology of systems implementation: lessons for IS research. Journal of Information Technology

[25] Jackson, S.L. (2009). Research Methods and Statistics: A Critical Thinking Approach 3rd edition. Belmont, CA: Wadsworth.

[26] Yamane, Taro. (1967). Statistics: An Introductory Analysis, 2nd Ed., New York 
[27] Harper Row Israel, and Glenn D. (2013)." Determining Sample Size". Program Evaluation and Organizational Development, IFAS, University of Florida. PEOD-5. Available at https://edis.ifas.ufl.edu/pd006

[28] Robert, K. (1984) "Case Study Research Design and Methods" Sage Publications -International Education and professional publisher London. Available online athttp://faculty.washington.edu/swhiting/pols502/Yin.pdf

[29] Porter and Stephen R. (2004). "Pros and Cons of Paper and Electronic Surveys." New Directions in Institutional Research, no. 121:91-97.

[30] Cochran, W. G. (1963). Sampling Techniques, 2nd Ed., New York: John Wiley and Sons, Inc.

[31] USAID (2013) "Making the Journey from Cash to Electronic Payments" USAID Implementing Partners and Craft Silicon, (2013). Payment Gateway Integration Specifications and Guide Integration of Business Systems and Bank with Payment Gateway, June 20, 2013 Version 2.3, Kenya Revenue Authority Document.

[32] Economist Intelligent Unit (EIU) (2014) Government Epayments Adoption Ranking (GEAR). Available at : www.eiu.com

[33] Jamain N. Zimmerman (2014) "Electronic G2P Payments: Evidence from Four Lower-Income Countries" Available at :http://www.cgap.org/publications/ electronic-g2ppayments-evidence-four-lower-income-countries

[34] ICTMP (2014). The Kenya National ICT Master Plan $2013-2018$

[35] CIAT (2014). The use of Information and Communication Technologies in the tax Administration: Prepaid phone credits as a means of payment. Kenya Revenue Authority.

[36] Pattarin, M. (2009) Implementation of Effective Change Management for Successful Integration of Health Information Technology (HIT) Systems in Hospitals.

[37] R. Phaal and G. Muller (2009), "An architectural framework for road Mapping: Towards visual Strategy," Technological Forecasting and Social Change, vol. 76, pp. 39-49, 2009

[38] Oliveira. And Martins, M, F. (2011)."Literature Review of Information Technology Adoption Models at Firm Level" The Electronic Journal Information Systems Evaluation Volume 14 Issue 1 2011, (pp110-121), available online at www.ejise.com.

[39] Csaba, C., O'Brien, Giller, J.B., McCarthy, Adam, F., (2013). "The use of E-Payment in the Distribution of social welfare in Ireland: Charting the daily experience of recipients", Transforming Government: People, Process and Policy, Vol. 7 Iss: 1, pp.6 - 26

[40] World Bank. (2013) "Electronic Payments with Limited Infrastructure Uganda's Search for a Viable E-payments Solution for the Social Assistance Grants for Empowerment" Washington, DC USA. Available online at http:// www.microfinancegateway.org

[41] World Bank (2012) "General guidelines for the development of government payment Programs" Washington DC USA accessed 9th July 2015 Available at. http://: www.worldbank.org.

[42] Beatriz Marulanda and Mariana Paredes (2015) "Columbia's Online E-payment Platform: Private Sector Innovation Inspired by Governments Vision". Better than Cash (BTCA) Case study. Available at http://www.betterthancash.org/better-than-cash-alliancecase-studies/

[43] Hsin-Lu C. and Michael J S. (2005) "A Roadmap to Adopting Emerging Technology in E-Business - An Empirical Study". Available at: http://www. business.uiuc.edu/Working_Papers/papers/05-0125.pdf

[44] Cohen J. West P.S.G. and Aiken, L. S. (2003).Applied multiple regression/correlation analysis for the behavioral sciences.

[45] C. Patrick Doncasterand and Rew J. H. Dave (2009). Analysis of Variance and Covariance: How to Choose and Construct Models for the Life Sciences

[46] Christine Mbulwa (2014) E-government services delivery in Kenya. Available at: https://su plus. Strathmore .edu/.../Framework

[47] Tornatzky, L. and Fleischer, M. (1990). The process of technology innovation. Lexington, M.A: Lexington Books.

[48] Accountability (2008) AA1000 Stakeholder Engagement Standard 2011. Available at: http://www.accountability. org/standards/aa1000ses.html

[49] Warkentin, M., Gefen, D., Pavlou, P. and Rose, G. (2002). Encouraging Citizen Adoption of e-Government by Building Trust, Electronic Markets, Volume. 12:3 